УДК 94(569.4)

DOI: $10.52575 / 2687-0967-2021-48-1-48-54$

\title{
Организация учебного процесса в высших школах ранневизантийского Берита (по Захарии Ритору)
}

\author{
Я.А. Дронова \\ Белгородский государственный национальный исследовательский университет, \\ Россия, 308015, г. Белгород, ул. Победы, 85 \\ E-mail: 803014@bsu.edu.ru
}

\begin{abstract}
Аннотация. Статья посвящена попытке реконструкции организации учебного процесса в юридической школе Берита (совр. Бейрут). Основания для изучения данного вопроса дают разнообразные литературные источники, написанные в нескольких жанрах и отличающиеся различной исторической ценностью. Юридическая школа наиболее известна нам из сохранившегося сирийского перевода сочинения Захарии Схоластика (Ритора) «Жизнь Севера» об известном антиохийском епископе. Текст проливает яркий свет на организацию учебного процесса и представляет собой несколько занимательных эпизодов из жизни преподавателей и студентов тогдашней знаменитой юридической школы в конце $\mathrm{V}$ века. Студенты попадали в Бейрутскую высшую школу, только пройдя предварительную подготовку, в частности, такие школы были в Александрии. В Бейруте в обучение шло 5 курсов, каждый курс носил свое название. Обучение велось 5 дней в неделю и основывалось на римской классической юридической традиции. Важную роль в жизни школы играло христианство, многие студентыправоведы посвятили себя впоследствии религиозной деятельности.
\end{abstract}

Ключевые слова: Ранняя Византия, Берит, Захария Схоластик, высшее образование, философия, риторика, юридические школы.

Для цитирования: Дронова Я.А. 2021. Организация учебного процесса в высших школах Ранневизантийского Берита (по Захарии Ритору). Via in tempore. История. Политология, 48 (1): 48-54. DOI: 10.52575/2687-0967-2021-48-1-48-54.

\section{Organization of the educational process in higher schools of the early Byzantine Beyrouth (by Zacharias Rhetor)}

\author{
Yana A. Dronova \\ Belgorod National Research University, \\ 85, Pobeda St., Belgorod, 308015, Russia \\ E-mail: 803014@bsu.edu.ru
}

\begin{abstract}
The article is devoted to the reconstruction of the organization of the educational process in the Beirut law school. The reasons for studying this issue are provided by a variety of literary sources written in several genres and differing in historical value. The school of law is best known to us from Zachariah's Syrian translation of «The Life of Severus», narrating about the Bishop of Antioch. It sheds a bright light on the organization of the educational process and presents several entertaining, sometimes striking episodes from the life of teachers and students of the famous law school at the end of the 5th century A. D. Students entered the Beirut High School only after undergoing preliminary training, in particular, such schools were in Alexandria. In Beirut, five courses were taught, each course had its own name. The education was conducted five days a week. Education was based on Roman classical legal tradition. Christianity played an important role for the school, many law students devoted themselves to religious activities.
\end{abstract}

Keywords: Early Byzantium, Beyrouth, Zacharias Scholasticus, higher education, philosophy, rhetoric, law schools. 
For citation: Dronova Ya.A. 2021. Organization of the educational process in the higher schools of the early Byzantine Beyrouth (by Zacharias Rhetor). Via in tempore. History and political science, 48 (1): 48-54 (in Russian). DOI: 10.52575/2687-0967-2021-48-1-48-54.

В данной статье мы предпринимаем попытку рассмотрения состояния и развития юридической школы в Берите в ранневизантийское время, а именно в период второй половины V-VI вв., с целью проследить особенности организации учебного процесса и их трансформации по сравнению с предшествующей эпохой. Хронологические рамки работы опираются на важный сохранившийся источник - агиографо-биографическое произведение монофизитского епископа V-VI вв. Захарии Митиленского «Жизнь Севера», посвященное его другу, знаменитому патриарху-монофизиту Северу Антиохийскому [Ambjörn, 2008]. Исследователи этого сочинения [Garitte, 1966], в частности, отмечали, что работа Захарии - «не столько биография, сколько апология». Ее можно также назвать в некотором роде памфлетом, написанным в ответ на обвинение Севера в том, что он не был последовательным христианином [Болгова, Болгов, 2013].

Автор биографии - Захария Схоластик (Ритор) - происходил из Маюмы, аванпорта города Газы в Южной Палестине. Его «житие» - это благочестивая дань уважения другу и сокурснику, «святому угоднику» Северу из Созополя (в Писидии). Север был назван Захарией внуком епископа Севера из Созополя. Такой епископ действительно отмечен источниками в 431 г. [Fedalto, 1988, I, p. 263]. Захария должен был знать, что Север имел языческое происхождение ${ }^{8}$.

Несмотря на то, что это сочинение носит специфический жанровый характер, оно тем не менее считается ценным историческим источником. Из него мы узнаем о жизни нескольких студентов и одного из выдающихся профессоров права. В этом трактате наиболее подробно среди всех позднеантичных источников характеризуется существование и функционирование Беритской юридической школы в современное автору время и в целом, что дает возможность проследить те изменения, которые произошли с ней в эпоху поздней античности.

Биография Захарии о Севере была первоначально написана на греческом языке, но давно утрачена, однако сохранилась в сирийском переводе ${ }^{9}$. Ученые конца XIX - начала $\mathrm{XX}$ века проявили большой интерес к этому необычному документу, который до начала XXI в. все еще в значительной степени игнорировался [Spanuth, 1893; Nau, 1899; Kugener,1904; Collinet, 1925]. В отечественной исторической науке до недавнего времени «Жизнь Севера» почти не привлекала внимания исследователей.

Берит был известен прежде всего как центр юридических исследований и обучения латинскому языку и литературе с III по VI вв. [Липшиц, 1984]. Берит прославился как «самый римский город», полис «romailkotera» из греческих городов Востока. Его школа набирала студентов ${ }^{10}$, желающих обучаться римскому праву у всемирно известных про-

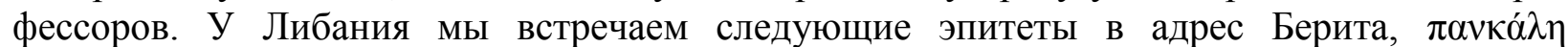

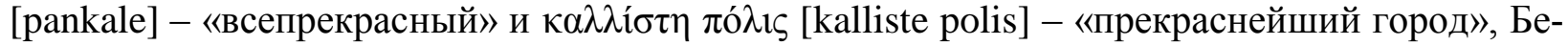

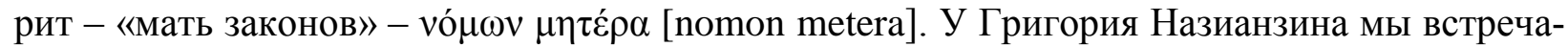

${ }^{8}$ О родословной Севера см. [Brock, Fitzgerald, 2013, p. 3].

${ }^{9}$ Сирийский текст объемом около пятидесяти печатных страниц был дважды отредактирован и 5 раз издан. Один раз в переводе на латынь (только отдельные отрывки), два раза на французский язык (полный текст) и дважды на английский (полностью - [Ambjörn, 2008; Brock, Fitzgerald, 2013]). Важные частичные переводы с сирийского на английский были сделаны Фрэнком Тромбли и Робином Дарлингом Янгом [Young, 1990]. Полный французский перевод «Vie de Severe» осуществил М.А. Кугенер [Kugener,1904].

${ }^{10}$ Известность Берита во многом была следствием важности его школы. Студенты прибывали в Беритскую юридическую школу из самых разных мест всей империи, преимущественно из восточных провинций, включая Анатолию, Египет и Армению. Они приезжали также и с Запада - из Рима, Иллирии [MacAdam, 2001, p. 209; Collinet, 1925, p. 243]. 
ем косвенные упоминания о Берите как «знаменитом городе приятной Финикии, месте действия римских законов» ${ }^{11}$. Захария Схоластик повторил фразу «мать законов», употребленную Либанием, но немного перефразировал ее в «кормилицу законов».

В городе Берите, наряду с богатыми земледельцами и духовенством, большим авторитетом пользовались профессора права и их студенты, связанные с государственным управлением.

Выходцы из Беритской высшей юридической школы являлись авторами наиболее известных позднеантичных комментариев и схолий к древнеримским юристам и законоведам: Гаю, Ульпиану, Папиниану, Павлу [Липшиц, 1976, с. 23]. Там же существовал и издательский центр. В работе Линды Хэлл [Hall, 2005, p. 36] доказывается, что некоторые рукописи юридических текстов были скопированы именно в Берите либо рабами профессоров права, либо другими переписчиками, которые, возможно, работали на книготворцев, государство или школы. О переписке книг, правда, языческого содержания, мимоходом упоминает и сам Захария (Zach. VS, 88).

Жалованье профессорам права платили сами их студенты, о чем свидетельствует переписка Либания ${ }^{12}$. Однако вполне вероятно, что некоторые профессора были назначены городским советом или правительством и таким образом являлись наемными работниками. Во всяком случае, на экономику Берита оказало влияние присутствие многих молодых людей. Такие студенты приводили с собой в город рабов, они могли покупать книги, посещать общественные увеселительные заведения. Студенты варьировались по богатству и социальному статусу - от сыновей сенаторской семьи из Константинополя до сыновей из простой провинциальной семьи.

В прологе к «Жизни Севера» упоминается, что дружба между Захарией и Севером возникла во время их первоначального обучения в Александрии. После смерти отца Севера его овдовевшая мать послала его с двумя братьями, которые были старше его, в Александрию, изучать грамматику и риторику ${ }^{13}$, как греческую, так и латинскую ${ }^{14}$. У большинства грекоязычных студентов были трудности в понимании латыни, и преподавателям приходилось специально решать эту проблему [Markopoulos, 2013, p. 32]. Латынь, как и прежде, была главным средством продвижения по службе в поздней античности. Но ее использование на грекоязычном Востоке империи было ограничено сферой государственной службы, судопроизводством и армией (в муниципальном самоуправлении греческий был разрешен с середины V в.).

Итак, Захария прибыл в Александрию, как и Север, для изучения грамматики и риторики (Zach. VS, 8-9). Север, вместе со своими с братьями, поступил учиться к софисту Иоанну, прозванному Семиографом, а затем к Сопатру (Zach. VS, 9) ${ }^{15}$. Случилось так, что в то время Захария тоже посещал курсы этого учителя.

Во время обучения Захарии и Севера в Александрии произошла их первая встреча. Захария и некоторые из его сокурсников восхищались любовью Севера к науке, а также

${ }^{11}$ Григорий Назианзин (328-389 гг.) - уроженец Каппадокии, известен в церковной традиции под именем Богослова, был включен церковью (вместе с Василием Кесарийским и Иоанном Златоустом) в число трех особо почитаемых «святителей». Григорий получил блестящее светское образование, увенчавшееся после школ Каппадокии, Кесарии Палестинской и Александрии десятилетним обучением в Афинах в высшей школе риторики.

12 Письма Либания свидетельствуют о том, что образование стоило немалых денег. Новые переводы тематических выборок из его многотомной переписки: [Bradbury, 2004; Cribiore 2007, p. 233-321].

${ }^{13}$ Грамматика, риторика и в меньшей степени философия требовались от всех поступающих в качестве предварительных условий для изучения права. Поэтому для приобретения данных знаний сначала отправлялись в такие школы, зачастую в Александрию. Студенты, не знающие латинского языка, начинали обучение с изучения перевода на греческий язык подручных юридических текстов. Эти указатели стали постоянным элементом учебной программы. О базовых элементах enkuklios paideia: [Watt, 2010].

${ }^{14}$ О латинском языке в Восточной Римской империи: [Rochette, 1997; Cameron Av., 2009, p. 15-36].

${ }^{15}$ Сопатр был широко известен как искусный ритор. 
его деликатностью. Они были удивлены, увидев, как за короткий промежуток времени Север проявил себя, добросовестно изучая теоретические труды и практические рекомендации старых риторов, стремясь подражать их блестящему стилю. Отвратившись ото всех зрелищ и развлечений, Север целиком посвятил себя учению. Вместе с Захарией они стали в дальнейшем изучать сочинения Либания, Василия и Григория в сравнительном аспекте (Zach. VS, 10-11).

Север на год ранее Захарии окончил обучение в Александрии и уехал в Берит, поступив в юридическую школу осенью 486 или 487 г. Отправляясь в Финикию, Север побуждал Захарию поехать с ним, однако Захария отказался, ссылаясь на то, что ему нужно еще некоторое время, чтобы изучить еще многие сочинения риторов и философов. Через год в Берит прибывает и Захария с целью изучения гражданского права, заинтересованный в юридической профессии для последующего поступления на государственную службу. Захария записался на курс Леонтия, сына Евдокия, который в то время был наиболее авторитетным профессором права и «был известен всем, кто имел какое-либо отношение к законам» (Zach. VS, 62) ${ }^{16}$. Из этой главы мы узнаем, что «большая школа» в Берите делилась на ряд более мелких «школ», связанных с тем или иным преподавателем; по сути, это представляет собой аналог современных кафедр. В сочинении Захарии такая малая школа называется «домом»: «Это был шестой день недели, называемый пятницей, когда почти все другие профессора имели обыкновение проводить свои уроки и лекции, каждый в своем собственном доме» (Zach. VS, 26). Здесь мы, несомненно, можем увидеть продолжение античной традиции личного (и даже частного) характера ученичества у конкретного учителя.

Прибыв в Берит, Захария отмечает, что он здесь не подвергся большинству традиционных студенческих неформальных обрядов и ритуалов, которыми «посвящали в студенты» «первокурсников». Такие обряды не носили издевательского характера, а просто создавали повод повеселиться для старших членов корпорации. Тот факт, что Захария избежал подобных обрядов, несомненно, отчасти объясняется его дружбой с Севером, к тому времени студентом второго курса, уже знакомым с академической и культурной атмосферой города (Zach. VS, 62). Покровительство студента более старшего курса было важным обстоятельством для новичка в корпоративной культуре школы.

Захария первые несколько дней провел, знакомясь с достопримечательностями ранневизантийского Берита. Портовый район, рядом с которым располагалась школа, был естественной достопримечательностью, там не было борделей и таверн, от которых Захария строго предостерегал будущего Патриарха Антиохийского, деловито занимающегося внеаудиторной деятельностью (Zach. VS, 66). Студенты, по-видимому, часто предавались мирским утехам, которые друг Севера, «первокурсник» Захария, считал совершенно нехристианскими и недопустимыми. Развлечений для таких мирских студентов и язычников в городе было много: ставки на «синих» или «зеленых» на ипподроме были из самых популярных. Были также представления в театрах дорогие спектакли в амфитеатрах. С такими развлечениями строгости юридической школы казались менее обременительными. Север поспешил доказать Захарии, что такими делами в принципе не занимается, но в то же время ответил, что полным монахом он быть также не может (Zach. VS, 67).

В Беритской школе полностью сохранилось преподавание на латинском языке и строгая римская система обучения, основанная на усвоении понятий и терминологии древнеримских юристов, что способствовало самоидентификации студентов, а в последующем - и их продвижению по государственной и церковной иерархии [Болгова, Болгов, 2013].

${ }^{16}$ Конечно, тогда, как и сейчас, хорошо известный преподаватель привлекал студентов не меньше, чем учреждение, с которым он был связан. Так, возможно, было и с Леонтием, и двумя его самыми знаменитыми учениками в 490-х гг. Захарией и Севером (Zach. VS, 62). 
Реформа законодательства и регламентация обучения праву была проведена при императоре Юстиниане в VI веке [Тюнина, 2018]. В конституции «Omnem» был утвержден порядок обучения и прохождения материала по годам (Just. Dig. Const. Omn. praef., 1-6) [Кофанов, 2002].

Юридический факультет работал пять с половиной дней в неделю, с утра понедельника до полудня субботы. Первокурсников называли «dipondii», что лучше всего переводится как «новички». Студенты второго курса много времени уделяли чтению книги Ульпиана «Libri ad Edictum», и поэтому их называли «ediktalioi» ${ }^{17}$. Студенты третьего курса были прозваны «papinianistae» за их усилия по интерпретации комментариев Папиниана. Четвертый год был отдан изучению других комментариев, вышедших из-под пера юриста Павла. Прозвище, которое студенты получили за это, было «lytai». Точное значение этого греческого термина вызывает некоторые споры, но оно, по-видимому, равнозначно латинскому «solutores», то есть «решатели» (юридических дел) ${ }^{18}$. Те студенты, которые пережили первые четыре года и выбрали дополнительный пятый, были известны как «prolytai» [Липшиц, 1976, с. 91].

Академические дни студентов-юристов были разделены между частным обучением и «классическим» дискуссионным. Утро было посвящено индивидуальному чтению ${ }^{19}$. Занятия в аудиториях или в зале суда на территории школы проводились во второй половине дня. Метод обучения был традиционным: чтение и толкование отрывков или слов, которые считались необходимыми для полного понимания конкретного текста закона [Киселева, 2018] ${ }^{20}$.

В обязанности таких преподавателей, как Леонтий, входило отбирать текст, вести дискуссии и, когда это было уместно, представлять мнение других выдающихся юристов, чьи труды к тому времени считались классическими. Во время комментариев преподавателей студенты должны были делать записи, которые затем использовались для домашней подготовки ${ }^{21}$.

Благодаря системе подготовки и изучению римских классиков ранневизантийские юристы достигали необычайной тонкости толкования законов, позволявшей им во всех деталях толковать перипетии судебного казуса и принимать наиболее справедливое решение, учитывающее все нюансы [Липшиц, 1984]. Именно такая традиция сохранялась в Берите.

В целом право этого времени все больше интересовалось вопросами религии. Само начало кодификации законов Юстиниана указывает на его религиозную мотивацию при составлении законов. Многие из прошедших юридическую подготовку в Берите впоследствии сменили свою роль юриста на религиозную деятельность. Север, чья биография так много говорит нам о жизни студентов-юристов в Берите, является в этом плане весьма репрезентативной фигурой, как и его биограф Захария Митиленский. Многие церковные историки прилагают к своим именам титул Схоластика; не исключением стал и сам Захария.

17 Это были базовые элементы enkuklios paideia, о которых (в связи с сирийским языком): [Watt, 2010].

${ }^{18}$ Информацию о программе обучения в течение четырех лет или, возможно, пяти лет cм. [Collinet, 1925, p. 223-243].

${ }^{19}$ Известно, что каждый студент имел базовую библиотеку из шести книг, предположительно выдержки из юридических документов, в общей сложности 60000 строк текста. Они могли быть расположены в параллельных колонках латинского и соответствующего греческого перевода (двуязычные комментарии) [MacAdam, 2001, p. 209]

${ }^{20} \mathrm{~B}$ конце V в. учебная программа была расширена и включала в себя философию. В работе Захарии термин «христианская жизнь» часто упоминается как «философская жизнь», и этот термин был особенно любим Захарией. Для более углубленного постижения права в контексте христианского образа жизни был создан кружок филопонов (трудолюбов) (Zach. VS, 27). Они же боролись с остатками язычества в городе в качестве добровольных общественных активистов.

21 Захария сообщает нам, что он составил заметки для студентов, поступающих в Беритскую школу. Неизвестно, было ли это обычной практикой, или Захария посчитал такой акт необходимым для благочестивого христианина [Wypszycka, 1996, p. 257-278]. 
Таким образом, можно установить факт переплетения религиозной практики и юридической подготовки. Но важную роль при этом продолжало играть классическое римское право и традиции античной юридической образовательной системы: преподавание на латинском языке, чтение и комментирование древних юристов, деление на несколько курсов, ежедневные занятия в аудиториях. Новшеством же стало христианское мировоззрение большинства студентов.

\section{Список литературы}

1. Болгова А.М., Болгов Н.Н. 2013. Позднеантичный Берит в Финикии и его юридическая школа. В: Государство и общество: взаимодействие и противостояние. Воронеж, ВГУ, 306-311.

2. Липшиц Е.Э. 1976. Право и суд в Византии в IV-VIII вв. Л., Наука, 232.

3. Липшиц Е.Э. 1984. Юридические школы и развитие правовой науки. В: Культура Византии IV - первая половина VII вв. М., Наука, 360-367.

4. Киселева Ю.П. 2018. Профессора права в Ранней Византии. В: Классическая и византийская традиция. 2018. Белгород, 335-338.

5. Кофанов Л.Л. (ред.). 2002. Дигесты Юстиниана. М., Статут, 584.

6. Тюнина О.С. 2018. Политика Юстиниана Великого в отношении школ права. В: Классическая и византийская традиция. 2018. Белгород, 338-343.

7. Ambjörn L. 2008. The Life of Severus by Zachariah of Mytilene. Piscataway, N.J., 123.

8. Bradbury S. 2004. Selected Letters of Libanius. Liverpool, UP, 289. UP, 175.

9. Brock S., Fitzgerald B., 2013. Two Early Lives of Severos, Patriarch of Antioch. Liverpool,

10. Cameron, Av. 2009. Old and New Rome: Roman studies in sixth-century Constantinople. In: P. Rousseau and M. Papoutsakis (eds). Transformations of Late Antiquity. Essays for Peter Brown (Farnham), 15-36.

11. Collinet P. 1925. Histoire de l'École de Droit de Beyrouth. Paris, Recueil Sirey, 333.

12. Cribiore R. 2007. The School of Libanius in Late Antique Antioch. Princeton, UP, 360. Brill, XIII, 201.

13. D’Alton J., Youssef Y. (eds.). 2016. Severus of Antioch. His Life and Times. Leiden; Boston, $325-641$.

14. Destephen S. 2008. Prosopographie chrétienne du Bas-Empire, 3. Diocèse d'Asie. Paris,

15. Fedalto G. 1988. Hierarchia Ecclesiastica Orientalis. Vol. I-II. Padua, 1208.

16. Garitte G. 1966. Textes hagiographiques orientaux rélatifs à saint Léonce de Tripoli, II. L'homélie copte de Sévère d'Antioche. Paris, Le Muséon, 79, 335-386.

17. Hall L. 2005. Roman Berytus. Beirut in Late Antiquity. London, Routledge, 375.

18. Kugener M. 1904. Vie de Sévère par Jean de Beth Aphtonia. Patrologia Orientalis, t. 2.3, 187.

19. MacAdam H.I. 2001/02. Studia et circenses: Beirut's Roman Law School in its colonial, cultural context. Aram, 13/14, 193-226.

20. Markopoulos A. 2013. In search for «Higher Education» in Buzantium. In: Зборник радова Византолошког института [Zbornik radova Vizantoloshkog instituta]. 50, $29-44$.

21. Nau F. 1899. Vie de Sévère patriarche d'Antioche. Revue de l'Orient chrétien, 4, 543-571.

22. Rochette B.1997. Le latin dans le monde grec. Brussels, P., 423.

23. Spanuth M. 1893. Das Leben des Severus von Antiochien in syrischer Übersetsung. Göttingen, 216.

24. Watt J. 2010. Rhetoric and Philosophy from Greek into Syriac. Farnham, Ashgate, 330.

25. Wypszycka E. 1996. Études sur le christianisme dans l'Égypte de l'Antiquité tardive. Rome, Edizione, 452.

26. Young R.A.D. 1990. Zacharias: The Life of Severus: Introduction and Translation. In: Ascetic Behavior in Gréco-Roman Antiquity: A Sourcebook. Minneapolis, Fortress Press, 312-328.

\section{References}

1. Bolgova A.M., Bolgov N.N. 2013. Pozdneantichnyj Berit v Finikii i ego juridicheskaja shkola [Late Antique Beirut in Phoenicia and his law school]. In: Gosudarstvo i obshhestvo: vzaimodejstvie i protivostojanie [State and society: interaction and opposition]. Voronezh, Voronezh State University, 306-311. 
2. Lipshits, E.E. 1976. Pravo i sud v Vizantii v IV-VIII vv. [Law and court in Byzantium in the IV-VIII centuries]. Leningrad, Nauka, 232.

3. Lipshits, E.E. 1984. Juridicheskie shkoly i razvitie pravovoj nauki [Law schools and the development of legal science]. B: Kul'tura Vizantii IV - pervaja polovina VII vv. [Culture of Byzantium IV - first half of VII centuries]. Moscow, Nauka, 360-367.

4. Kiseleva, Yu.P. 2018. Professora prava v Rannej Vizantii [Professors of Law in Early Byzantium]. In: Klassicheskaja i vizantijskaja tradicija. 2018 [Classical and Byzantine tradition. 2018]. Belgorod, 335-338.

5. Kofanov, L.L. (ed.). 2002. Digesty Justiniana [Digests of Justinian]. Moscow, Statute, 584.

6. Tyunina O.S. 2018. Politika Justiniana Velikogo v otnoshenii shkol prava [The policy of Justinian the Great in relation to the schools of law]. In: Klassicheskaja i vizantijskaja tradicija. 2018 [Classical and Byzantine tradition. 2018]. Belgorod, 338-343.

7. Ambjörn L. 2008. The Life of Severus by Zachariah of Mytilene. Piscataway, N.J., 123.

8. Bradbury S. 2004. Selected Letters of Libanius. Liverpool, UP, 289.

9. Brock S., Fitzgerald B., 2013. Two Early Lives of Severos, Patriarch of Antioch. Liverpool, UP, 175.

10. Cameron, Av. 2009. Old and New Rome: Roman studies in sixth-century Constantinople. In: P. Rousseau and M. Papoutsakis (eds). Transformations of Late Antiquity. Essays for Peter Brown (Farnham), 15-36.

11. Collinet P. 1925. Histoire de l'École de Droit de Beyrouth. Paris, Recueil Sirey, 333.

12. Cribiore R. 2007. The School of Libanius in Late Antique Antioch. Princeton, UP, 360.

13. D’Alton J., Youssef Y. (eds.). 2016. Severus of Antioch. His Life and Times. Leiden; Boston, Brill, XIII, 201.

14. Destephen S. 2008. Prosopographie chrétienne du Bas-Empire, 3. Diocèse d'Asie. Paris, $325-641$.

15. Fedalto G. 1988. Hierarchia Ecclesiastica Orientalis. Vol. I-II. Padua, 1208.

16. Garitte G. 1966. Textes hagiographiques orientaux rélatifs à saint Léonce de Tripoli, II. L'homélie copte de Sévère d'Antioche. Paris, Le Muséon, 79, 335-386.

17. Hall L. 2005. Roman Berytus. Beirut in Late Antiquity. London, Routledge, 375.

18. Kugener M. 1904. Vie de Sévère par Jean de Beth Aphtonia. Patrologia Orientalis, t. 2.3, 187.

19. MacAdam H.I. 2001/02. Studia et circenses: Beirut's Roman Law School in its colonial, cultural context. Aram, 13/14, 193-226.

20. Markopoulos A. 2013. In search for «Higher Education» in Buzantium. In: Зборник радова Византолошког института [Zbornik radova Vizantoloshkog instituta]. 50, 29-44.

21. Nau F. 1899. Vie de Sévère patriarche d'Antioche. Revue de l'Orient chrétien, 4, 543-571.

22. Rochette B.1997. Le latin dans le monde grec. Brussels, P., 423.

23. Spanuth M. 1893. Das Leben des Severus von Antiochien in syrischer Übersetsung. Göttingen, 216.

24. Watt J. 2010. Rhetoric and Philosophy from Greek into Syriac. Farnham, Ashgate, 330.

25. Wypszycka E. 1996. Études sur le christianisme dans l'Égypte de l'Antiquité tardive. Rome, Edizione, 452.

26. Young R.A.D. 1990. Zacharias: The Life of Severus: Introduction and Translation. In: Ascetic Behavior in Gréco-Roman Antiquity: A Sourcebook. Minneapolis, Fortress Press, 312-328.

\section{ИНФОРМАЦИЯ ОБ АВТОРЕ}

Дронова Яна Алексеевна, аспирантка кафедры всеобщей истории Белгородского государственного национального исследовательского университета, г. Белгород, Россия

\section{INFORMATION ABOUT THE AUTHOR}

Yana A. Dronova, Post-graduate student of the Department of General History of the Belgorod State National Research University, Belgorod, Russia 